\title{
Development and validation of diagrammatic scales to assess septoriose in tomato
}

\section{Monteiro FP' 1 , Ogoshi $C^{1}$, Cardoso $\mathbf{D A}^{2}$, Valdecir $\mathbf{P}^{3}$, Pinto FAMF $^{4}$ and Mallmann $\mathbf{G}^{\mathbf{1}}$}

\begin{abstract}
${ }^{1}$ Researchers at the EPAGRI - Agricultural Research and Rural Extension Enterprise of Santa Catarina, Abílio Franco, 1500, Bom Sucesso, PO Box 591, Zip code 89.501-032, Caçador, Santa Catarina, Brazil

${ }^{2}$ Undergraduate student at the UFSC - Universidade Federal de Santa Catarina, Bernardo Olsen, 400, Centro, Canoinhas, Santa Catarina, Brazil

${ }^{3}$ Undergraduate student at the UNOESC - Universidade do Oeste de Santa Catarina, Paese, 198, Universitário, Videira, Santa Catarina, Brazil

${ }^{4}$ Researchers at the EPAGRI - Agricultural Research and Rural Extension Enterprise of Santa Catarina, João Araújo Lima, 102, Jardim Caiçara, Zip code 88.600-000, São Joaquim, Santa Catarina, Brazil
\end{abstract}

Monteiro FP, Ogoshi C, Cardoso DA, Valdecir P, Pinto FAMF, Mallmann G 2021 - Development and validation of diagrammatic scales to assess septoriose in tomato. Plant Pathology \& Quarantine 11(1), 115-124, Doi 10.5943/ppq/11/1/13

\begin{abstract}
Septoriose or septoria leaf spot (Septoria lycopersici Speg.) is an important disease in tomatoes (Solanum lycopersicum L.) because of the damage that it can cause. To improve the evaluation of studies aiming to determine the most efficient treatment is necessary accuracy and precision during the assessment. Therefore, this study aimed to develop two diagrammatic scales based on grades and severity to evaluate septoriose severity on tomato leaves. The diagrammatic scale based on grades was developed and validated with eight grades, with severities ranging from 0.67 to $100 \%$. The diagrammatic scale based on severity values varied from 1.79 to $100 \%$. More than $80 \%$ of the leaves collected from the field showed severity ranging from 0.1 to $20 \%$, but there was a representative leaf for every interval chosen. Five inexperienced evaluators performed the validation of the scales, and the data were analysed with Lin's statistics. Without the scales, most evaluators overestimated disease severity, whereas the use of the scales resulted in increased precision, accuracy, and reliability of the estimates. In conclusion, the proposed diagrammatic scales proved to be useful for assessments of septoriose severity in tomato leaves. The scales may be of interest to researchers performing studies on epidemiology, fungicides efficacy or breeding for resistance.
\end{abstract}

Keywords - disease assessment - disease severity - phytopathometry - Septoria leaf spot

\section{Introduction}

The Septoria lycopersici causes septoriose, one of the most devastating diseases in tomatoes worldwide. It is a severe disease everywhere tomatoes grow (Stevenson 1991). This pathogen is a constant concern, especially when in favourable environmental conditions and the same area are continuously cultivated with tomatoes (Lopes \& Ávila 2005). The most favourable weather conditions occur when the relative humidity is above $85 \%$ and the temperature is between 20 to 
$25^{\circ} \mathrm{C}$ (Kurozawa \& Pavan 2005). Under these favourable conditions, the disease causes severe defoliation that can reach $100 \%$, and consequently, losses are significant due to the scalding of tomato fruits by the sun (Sohi \& Sokhi 1974).

In each cultivation cycle, the disease begins in the leaves of the plant shallow due to raindrops falling on plant fragments with Septoria spores and causing spores to spread (Douglas 2008). S. lycopersici infect tomato leaves by both stomata and direct penetration (MartinHernandez et al. 2000). Symptoms appear one week after inoculation and after six weeks defoliation is close to $100 \%$ when in wet conditions and control measures are not employed (Parker et al. 1997). Symptoms on leaves are circular-shaped spots with darkened edges and a brown/grey coloured centre. After a few days, small black dots appear in the centre of the lesions, which correspond to the reproductive structures of the fungus (pycnidia). Under favourable conditions, lesions may coalesce, turn yellow, then brown, wither, dry and detach from the plant (Douglas 2008). Similar lesions may occur on the stem. Fruits are rarely affected. It may be confused with bacterial spot or with early blight caused by Alternaria spp. when lesions are early (Lopes \& Ávila 2005).

Methods for disease quantification should be easy, accurate, reproducible, and quickly applied under different conditions (Berger 1980, Campbell \& Madden 1990). Diagrammatic scales or standard area diagrams (SADs) are handy tools to minimize the subjectivity of severity estimates (Barbosa et al. 2006). A diagrammatic scale must be elaborated considering the following requirements: the number of leaves collected to develop the scale has to be representative; the upper limit illustrated in the scale must correspond to the maximum disease severity found in the field; real severities needs to be represented in the scale with accuracy (Horsfall \& Barratt 1945).

There are no validated diagrammatic scales available to assess septoriose severity in tomato leaves. There are, however, reports of the use of the descriptive scales or adaptations of scale made for other pathosystems to evaluate the disease (Maluf et al. 1985, Boff et al. 1991, Mello et al. 1997, Gondal et al. 2012). The availability of validated diagrammatic scales would help to develop studies on disease epidemiology, fungicides efficacy and breeding for resistance because validated scales provide accurate, precise and reproducible estimates of disease severity (Salgado et al. 2009, Santos et al. 2010).

The objective of this study was to develop and validate two diagrammatic scales to assess the severity of septoriose on tomato leaves.

\section{Materials \& Methods}

\section{Leaf sampling, image analyses and scales elaboration}

To elaborate the scale, 1313 tomato leaves with different severities of septoriose were obtained from the field at Caçador, Santa Catarina, Brazil. The aetiology of the disease was confirmed by spore morphology and via Kock's postulates. Leaves with septoriose were photographed and loaded into the software Measure picture v. 1.0 (Kassler 2016) to determine their health and lesioned leaf areas, which resulted in the real severity for each leaf. Lesions included the chlorotic area as part of the symptoms. We proposed two different scales based on severity percentages and grades. When evaluators use the latter, the estimates were given in grades, which comprise a range of severity. The distribution of frequencies of lesioned leaves determined the diagrammatic scales grades and severities intervals. A diagrammatic scale based on grade was made with eight grades (level $0-0.0 \%$, level $1-0.1-3.99 \%$, level $2-4.0-7.99 \%$, level $3-8.0-$ $18.99 \%$, level $4-19-39.99 \%$, level $5-40-59.99 \%$, level $6-60-89.99 \%$ and $7-\geq 90$ ) and diagrammatic scale based on severity only was made with nine illustrations with the severity of 0 , $1.79,3.93,10.91,20.63,43.63,63.14,84.05$ and $100 \%$.

\section{Evaluation of the diagrammatic scales}

\section{Estimates performed by five inexperienced evaluators}


Each of the five inexperienced evaluators gave estimates of 100 images of leaves, without and with scales based on severity and grades. These images were randomly chosen and contained different disease severity. The first set of assessments was performed without the aid of a diagrammatic scale. After seven days, the same evaluators received the same images rearranged to perform estimates with the aid of the proposed scale based on severity. Then, seven days later, they did a second assessment with the scale based on grades. Those estimates were analysed with Lin's statistics to validate the scales, comparing the estimates with and without using the scales.

\section{Analysis with Lin's statistics}

Analyses were performed comparing the evaluators' performance without and with the use of the scales to measure agreement, precision, accuracy, bias, and interevaluator reliability of the estimates. Lin's concordance correlation (LCC) analysis (Lin 1989) calculated the agreement between the estimate and true severity for each evaluator. LCC coefficient assesses the fitness of pairs of observations to the line of concordance $\left(45^{\circ}=\right.$ perfect concordance $)$ by combining the measurements of accuracy and precision. It is a method to judge the agreement between estimates and true values and has been previously employed in plant disease severity assessments (Spolti et al. 2011, Yadav et al. 2013). Pearson's correlation coefficient, an indicator of precision, and the bias correction that measures accuracy were used to calculate Lin's concordance correlation coefficient. The bias correction factor $(\mathrm{Cb})$ is calculated from location bias (where $0=$ perfect match between $\mathrm{x}$ and $\mathrm{y}$ ) and scale bias (where $1=$ perfect match between $\mathrm{x}$ and $\mathrm{y}$ ) and are derived from the means and standard deviations of $\mathrm{x}$ and $\mathrm{y}$, respectively. The absolute error was also calculated (the estimated value minus the real severity). The interevaluator reliability indicates the reproducibility of the visual estimates between evaluators matched in pairs with and without the use of the scales (Shrout \& Fleiss 1979). The scale's influence on the interevaluator reliability was measured with the LCC coefficient. All statistical analyses were performed with the R software (R Core Team 2013), and the epi.ccc function of the epiR package (Stevenson et al. 2012) was used to obtain Lin's CC statistics.

\section{Results}

Septoriose severity for the 1313 tomato leaves ranged from 0.01 to $100 \%$. Approximately $63 \%$ of the leaves showed severities between 0.00 and $10 \%$ (Table 1). The lowest and the highest severities of symptomatic leaves represented in the diagrammatic scale based on severity percentages were 1.79 and $100 \%$, respectively (Fig. 1a). For the diagrammatic scale based on grades, those values varied from 0.67 to $100 \%$ (Fig. 1b). The scales were developed to represent values that commonly occur in the field. Since septoriose can occur any time during tomato cultivation, it can severely defoliate the plant reaching $100 \%$ of severity.

Table 1 Distribution of septoriose frequencies in 1313 tomato leaves used to develop the scales

\begin{tabular}{lcc}
\hline Disease severity (\%) & N of leaves & \% \\
\hline $0.00-10 \%$ & 828 & 63 \\
$10.01-20 \%$ & 160 & 12 \\
$20.01-30 \%$ & 78 & 6 \\
$30.01-40 \%$ & 40 & 3 \\
$40.01-50 \%$ & 27 & 2 \\
$50.01-60 \%$ & 32 & 2 \\
$60.01-70 \%$ & 14 & 1 \\
$70.01-80 \%$ & 15 & 1 \\
$80.01-90 \%$ & 11 & 1 \\
$90.01-100 \%$ & 108 & 8 \\
\hline Total of leaves assessed & $\mathbf{1 3 1 3}$ & $\mathbf{1 0 0 \%}$ \\
\hline
\end{tabular}

*Approximately value 
The estimates of 500 tomato leaves were nearest to the actual value and the absolute errors (the estimated value minus the real severity) were lower when evaluators used both diagrammatic scales (Figs 2, 3a, b, c). Without scale, the evaluators tend to overestimate the severity.

The most expressive gain in agreement, accuracy and precision when they used the scales was obtained for the evaluators with the poorest estimates when without the use of the scale (Fig. 3d, e, f).

Lin's statistics is a set of calculations used to validate the scales. Except for scale shift, all Lin's statistics (location shift, bias correction, Lin's concordance correlation coefficient) and Pearson's correlation were improved, on average, with the use of the scales (Table 2). The bias correction is a measure of accuracy, and it showed significantly higher values, on average, with the use of the scales $\left(\mathrm{C}_{\mathrm{b}}=0.98\right.$ for severity scale and $\mathrm{C}_{\mathrm{b}}=0.99$ for grade scale) than without the scale $\left(\mathrm{C}_{\mathrm{b}}=0.89\right)$. Similarly, Lin's $P_{c}$ that measures the agreement was higher with the scales $\left(P_{c}=0.90\right)$ than without it $\left(P_{c}=0.79\right)$. Pearson's correlation coefficient, which measures precision was also higher with the scales $(r=0.93$ and 0.91$)$ than without it $(r=0.89)$.

The reproducibility of the scales tested with correlation concordance coefficient by comparing pairs of evaluators had values varied from 0.47 to $0.91 \%$ (average of $0.65 \%$ ) for assessments without the scale and from 0.80 to $0.94 \%$ (average $0.87 \%$ ) and from 0.78 to $0.92 \%$ (average $0.87 \%$ ) with the use of the scale based on severity and with the scale based on grades, respectively (Table 3)

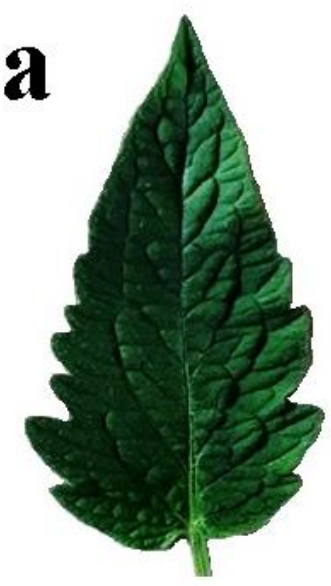

$0 \%$

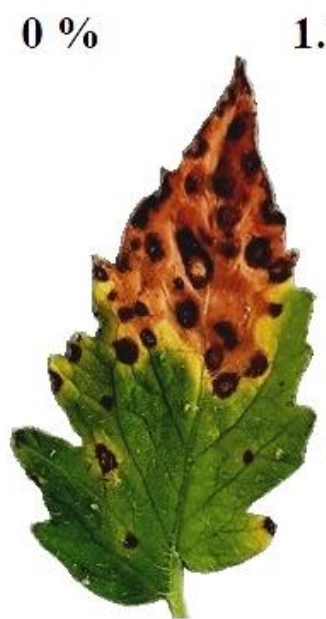

$43.63 \%$

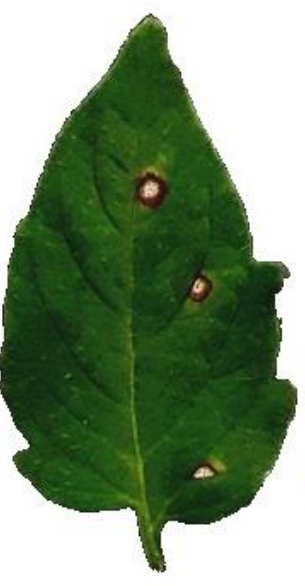

$1.79 \%$

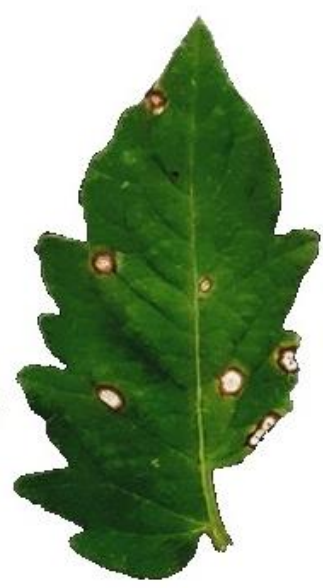

$3.93 \%$

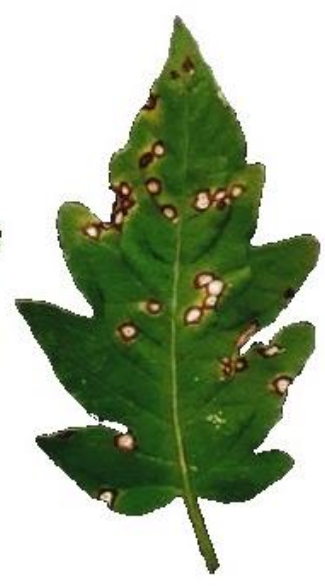

$10.91 \%$

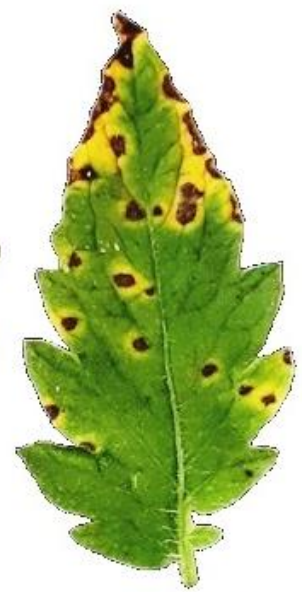

$20.63 \%$

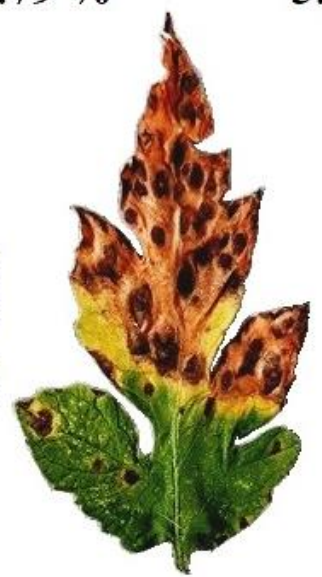

$63.14 \%$

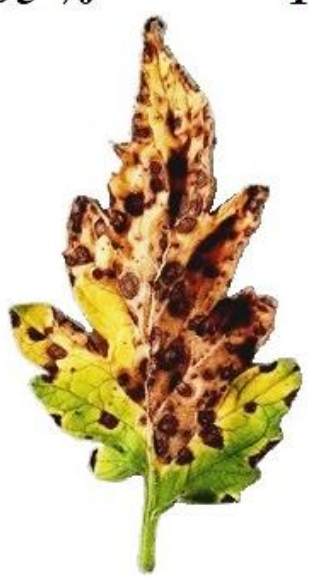

$84.05 \%$

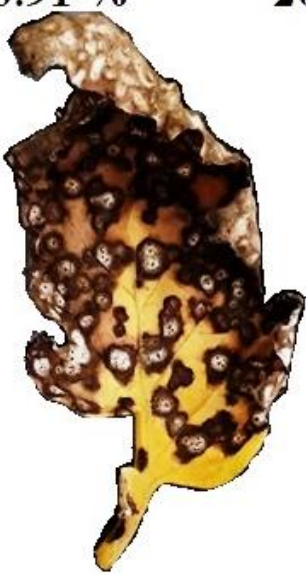

$100 \%$

Fig. 1 - Diagrammatic scales for the assessment of septoriose in tomato leaves. Scale based on severity percentages (a) and scale based on grades representing a range of severity (b). Numbers below each picture represent the real percentage of leaf area affected by the disease. The yellow colour was considered part of the disease. 


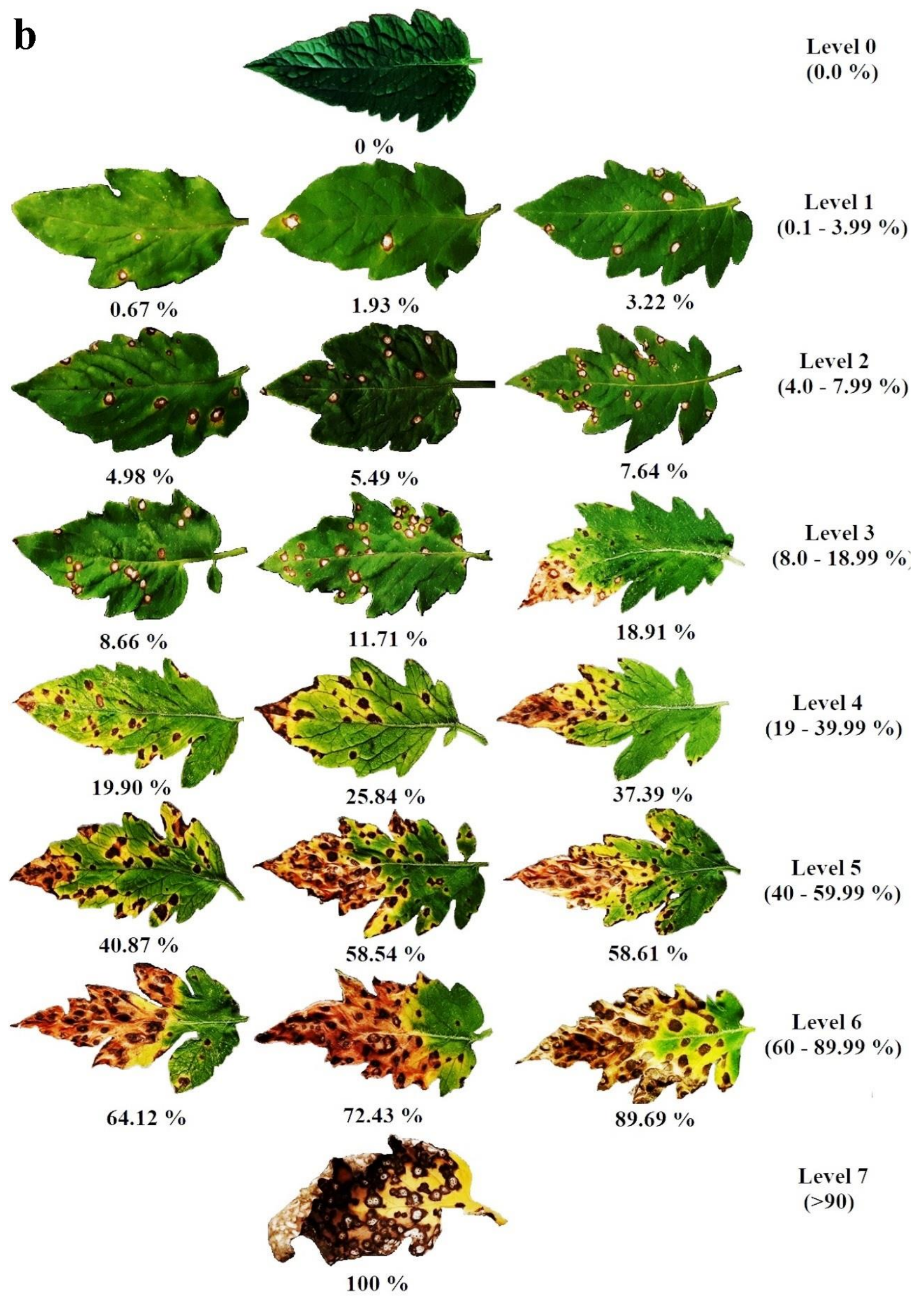

Fig. 1 - Continued. 


\section{Evaluation without scale}
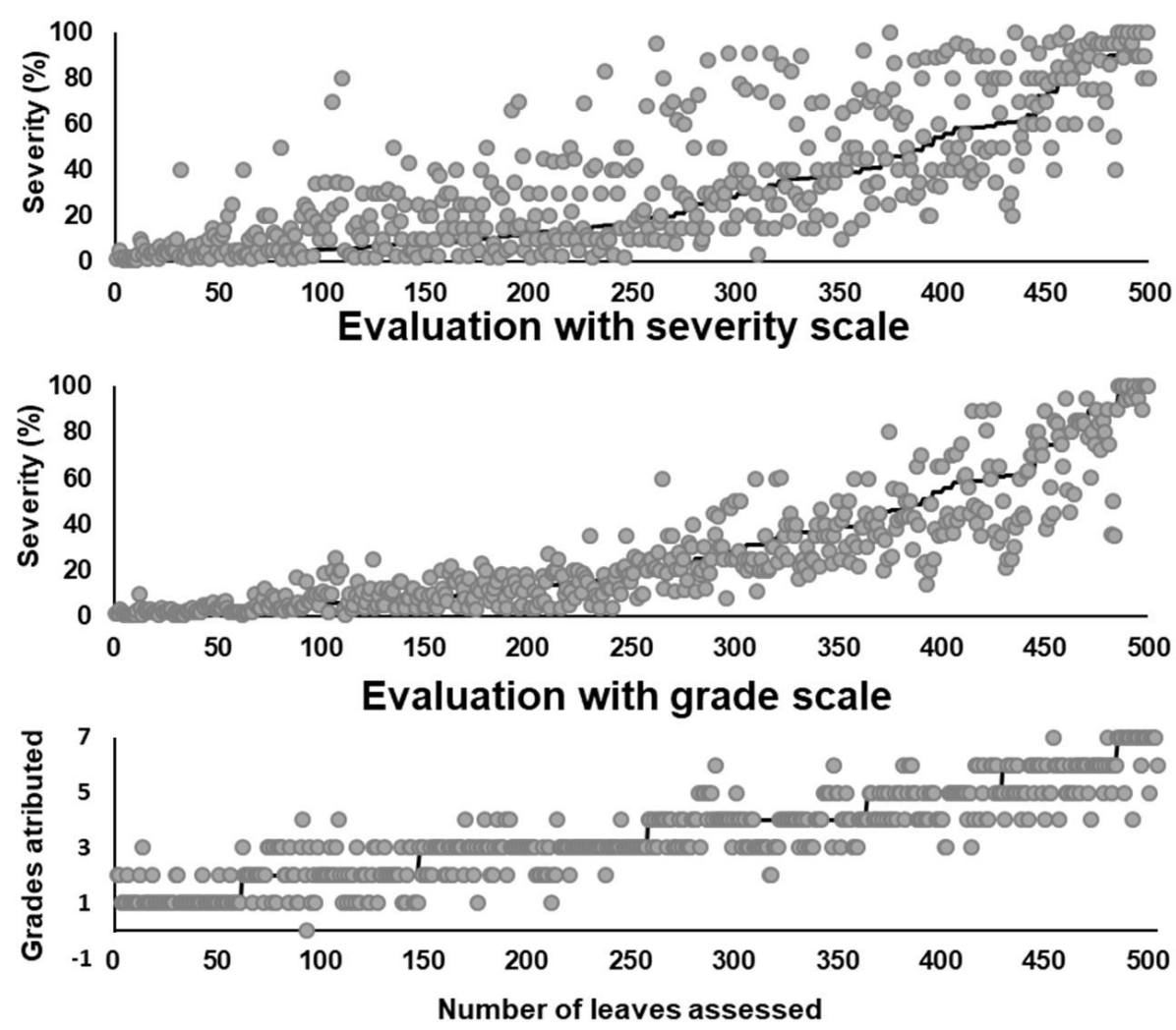

Fig. 2 - Assignment of 500 estimates given by the five evaluators compared to the real severity without the use of scales and with it. The black line is the real severity assessed digitally.

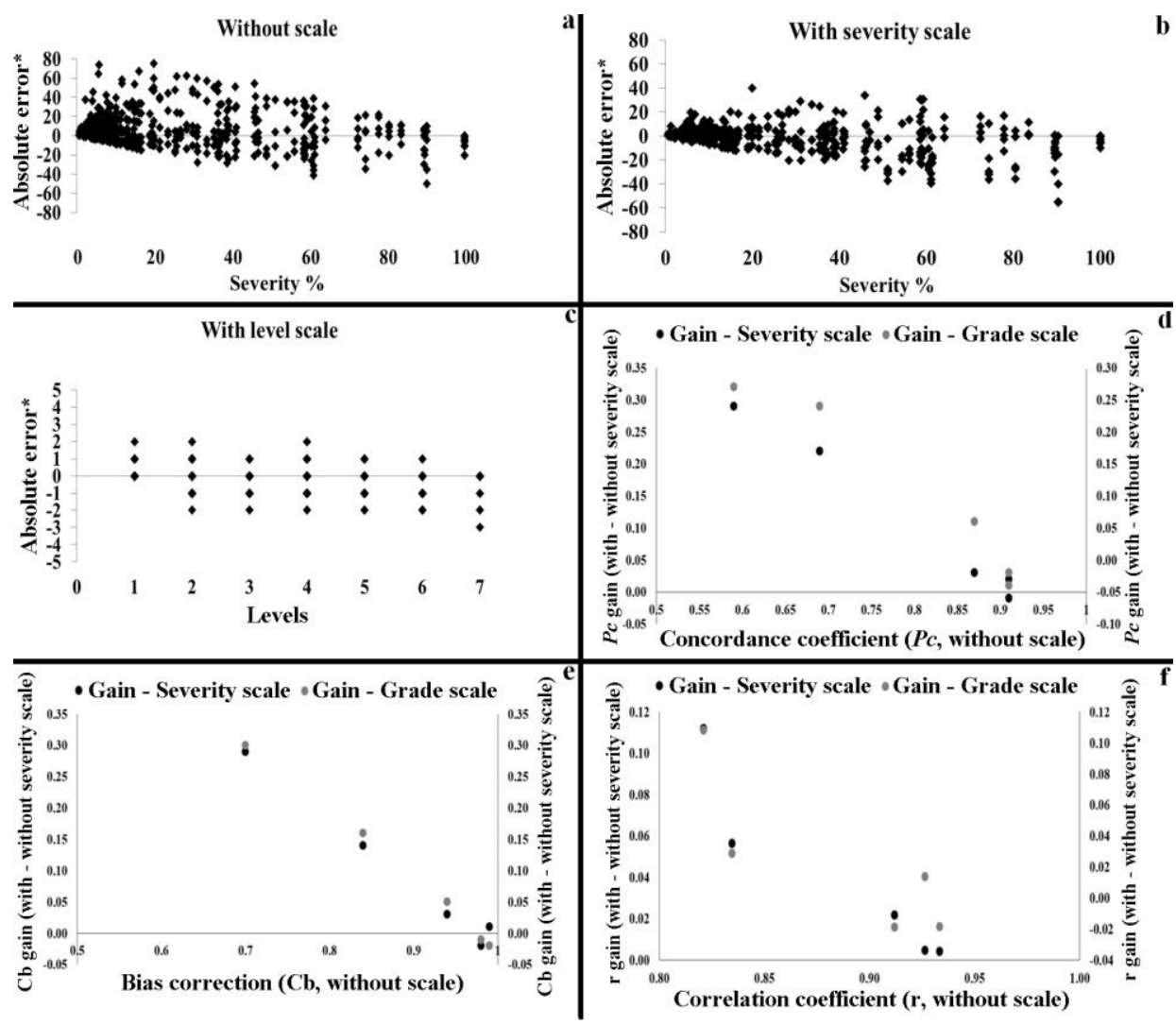

Fig. 3 - Distribution of residuals of the estimates obtained from evaluators in 500 estimations done without a scale (a), with the severity scale (b) and with grade scale (c). Average distribution of 
residuals (estimated severity - true severity) of septoriose (Septoria lycopersici) and gain in Lin's statistics in estimations done with and without the scales. Gain on estimates obtained with the use of scale in agreement measured with Lin's concordance correlation coefficient (d); and accuracy measured by bias correction (e); and precision measured by Pearson's correlation coefficient (f).

Table 2 Lin's concordance coefficients of the estimated severity of septoriose in tomato leave evaluated by five evaluators with and without the proposed scales

\begin{tabular}{|c|c|c|c|c|c|c|c|c|c|c|c|c|c|c|c|}
\hline \multirow[t]{2}{*}{ Evaluator } & \multicolumn{5}{|c|}{ Without } & \multicolumn{5}{|c|}{ With scale based on the severity } & \multicolumn{5}{|c|}{ With scale based on grade } \\
\hline & $\boldsymbol{P}_{c}^{2}$ & $C_{b}{ }^{3}$ & S.shift ${ }^{4}$ & L. shift ${ }^{5}$ & Pearson $^{6}$ & $\boldsymbol{P}_{c}$ & $C_{b}$ & S.shift & L. shift & Pearson & $\boldsymbol{P}_{c}$ & $C_{b}$ & S.shift & L. shift & Pearson \\
\hline A & 0.91 & 0.98 & 1.02 & -0.20 & 0.93 & 0.90 & 0.96 & 0.91 & -0.27 & 0.94 & 0.89 & 0.97 & 0.88 & -0.22 & 0.92 \\
\hline B & 0.59 & 0.70 & 1.14 & 0.91 & 0.83 & 0.88 & 0.99 & 0.89 & -0.10 & 0.89 & 0.86 & 1.00 & 1.00 & -0.01 & 0.86 \\
\hline $\mathrm{C}$ & 0.91 & 0.99 & 0.89 & 0.03 & 0.91 & 0.93 & 1.00 & 0.92 & 0.01 & 0.93 & 0.87 & 0.97 & 0.95 & -0.24 & 0.89 \\
\hline $\mathrm{D}$ & 0.87 & 0.94 & 0.78 & -0.25 & 0.93 & 0.90 & 0.97 & 0.83 & -0.16 & 0.93 & 0.93 & 0.99 & 0.96 & -0.12 & 0.94 \\
\hline $\mathrm{E}$ & 0.69 & 0.84 & 1.06 & 0.61 & 0.82 & 0.91 & 0.98 & 1.15 & 0.16 & 0.93 & 0.93 & 1.00 & 1.06 & 0.04 & 0.93 \\
\hline Means & 0.79 & 0.89 & 0.98 & 0.22 & 0.89 & 0.90 & 0.98 & 0.94 & -0.07 & 0.93 & 0.90 & 0.99 & 0.97 & -0.11 & 0.91 \\
\hline $\begin{array}{l}\text { Global } \\
\text { evaluation } 1\end{array}$ & 0.76 & 0.97 & 1.10 & 0.23 & 0.79 & 0.91 & 1.00 & 0.96 & -0.06 & 0.91 & 0.90 & 1.00 & 0.98 & -0.11 & 0.90 \\
\hline
\end{tabular}

${ }^{1}$ Global evaluation was performed analysing the data as one without discriminate evaluators.

${ }^{2}$ Concordance correlation coefficient $\left(P_{c}\right)$ combines precision and accuracy to measure agreement with the true values.

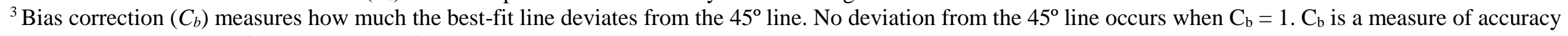
calculated from scale shift and location shift.

${ }^{4}$ Scale shifts relative to the perfect match $(1=$ perfect match between $x$ and $y)$.

${ }^{5}$ Location shift relative to the perfect match $(0=$ perfect match between $x$ and $y)$.

${ }^{6}$ Pearson's correlation coefficient measures precision $(r)$.

Table 3 Concordance correlation coefficient between evaluators matched in pairs of visual estimates of septoriose severity on 100 leaves of tomato by five evaluators

\begin{tabular}{llllll}
\hline Without scale & A & B & C & D & E \\
\hline A & 1 & 0.47 & 0.85 & 0.85 & 0.57 \\
B & - & 1 & 0.50 & 0.39 & 0.77 \\
C & - & - & 1 & 0.91 & 0.68 \\
D & - & - & - & 1 & 0.52 \\
E & - & - & - & - & 1 \\
\hline
\end{tabular}


Table 3 Continued.

\begin{tabular}{llllll}
\hline With scale based on severity & A & B & C & D & E \\
\hline A & 1 & 0.89 & 0.88 & 0.92 & 0.80 \\
B & - & 1 & 0.90 & 0.94 & 0.82 \\
C & - & - & 1 & 0.92 & 0.86 \\
D & - & - & - & 1 & 0.81 \\
E & - & - & - & - & 1 \\
\hline With scale based on grade & A & B & C & D & E \\
\hline A & 1 & 0.87 & 0.88 & 0.92 & 0.85 \\
B & - & 1 & 0.78 & 0.89 & 0.88 \\
C & - & - & 1 & 0.89 & 0.82 \\
D & - & - & - & 1 & 0.91 \\
E & - & - & - & - & 1 \\
\hline
\end{tabular}

\section{Discussion}

In this study, two diagrammatic scales to evaluate septoriose severity in tomato leaves were elaborated and validated. Those are the first validated diagrammatic scales made available to assess septoriose severity for tomato plants. The proposed diagrammatic scales were elaborated with real images of tomato leaves, which facilitates the assessments and improves precision and accuracy. On the other hand, most scales reported in the scientific literature do not use real images of plant parts to illustrate disease severity.

The scale based on grades was developed with eight grades and three severity values per grade (except for the first and last one), which help the evaluators to interpolate their samples and obtain better severity estimates. The development of scales with grades has increased in the last years (Nuñez et al. 2017). The assessments of septoriose severity with the scales were done with acceptable accuracy and precision by evaluators without any previous experience, showing the usefulness of the proposed diagrammatic scales. Without using a scale, evaluators tend to overestimate disease severity, especially at severity lower than $20 \%$, whereas at mid-to-high severity, estimates tend to be underestimated (Salgado et al. 2009, Santos et al. 2010, Menge et al. 2013). The use of a diagrammatic scale provides speed and allows users to standardize their estimates. In this study, the evaluators were considered to have had a good performance as their estimates were in the $6.10 \%$ interval of the real severity values, whereas to be considered as excellent evaluators, their estimates should have been in the 5\% interval (Nutter Junior \& Worawitlikit 1989). One of the reasons for the good performance of the evaluators may be related to the large size of the lesions, which according to other authors (Sherwood et al. 1983, GonzálezDomíngue et al. 2014) facilitates rating and increases precision. In this context, training the evaluators to use the scales may further reduce the subjectivity of the estimates by improving their performance (Nutter Junior \& Schultz 1995). Some evaluator (A) might have a natural ability, giving good estimates even without scales, and in this situation, the scale had little effect to improve the estimate of the individual.

Validation of the scale based on grade and severity values yielded similar conclusions about the performance of the evaluators. Both scales were useful to evaluate septoriose and had similar results. The use of one or another depends on the preference of the evaluator. There were no differences 
between the scales, and both showed improvements in precision, accuracy and reproducibility. Some authors do not consider regression analysis an appropriate approach for testing agreement, which combines precision and accuracy, and recommends Lin's statistics for scale validation (Lin 1989, Bock et al. 2010). Researchers working on breeding programs and phytopathology (epidemiology) will possibly benefit from using the proposed scales in experiments designed to assess septoriose severity and allow comparisons across different experiments.

The proposed diagrammatic scales proved to be useful for assessments of septoriose severity in tomato leaves. The scale may interest research performing studies on epidemiology, fungicides efficacy, or breeding for resistance.

\section{Acknowledgements}

The authors are thankful to the Agricultural Research and Rural Extension Enterprise of Santa Catarina (EPAGRI) and Foundation for Research and Innovation Support of the State of Santa Catarina (FAPESC) for financing and encouraging the execution of the project that gave rise to this publication.

\section{References}

Barbosa MAG, Michereff SJ, Mora-Aguilera G. 2006 - Elaboration and validation of diagrammatic key to evaluate white rust severity in Chrysanthemum. Summa Phytopathologica 32, 57-62.

Berger RD. 1980 - Measuring disease intensity. In: Teng PS, Krupa SV (eds) Crop Loss Assessment. St Paul, University Minnesota, 28-31.

Bock CH, Gottwald TR, Parker PE, Ferrandino F et al. 2010 - Some consequences of using the Horsfall-Barratt scale for hypothesis testing. Phytopathology, 100, 1030-1041.

Boff P, Zambolim L, Vale FXR. 1991 - Escalas para avaliação de severidade da mancha de estenfílio (Stemphylium solani) e da pinta preta (Alternaria solani) em tomateiro. Fitopatologia Brasileira 16, 280-283.

Campbell CL, Madden LV. 1990 - Introduction to Plant Disease Epidemiology. New York, NY, John Wiley.

Douglas SM. 2008 - Septoria leaf spot of tomato. Journal of the Connecticut Agricultural Experiment Station, 1-3.

Gondal AS, Ijaz M, Riaz K, Khan AR. 2012 - Effect of different doses of fungicide (Mancozeb) against Alternaria leaf blight of tomato in tunnel. Journal of Plant Pathology and Microbiology 3, 1-3.

González-Domínguez E, Martins RB, Del Ponte EM, Michereff SJ et al. 2014 - Development and validation of a standard area diagram set to aid assessment of severity of loquat scab on fruit. European Journal of Plant Pathology 139, 419-428.

Horsfall JC, Barratt RW. 1945 - An improved grading system for measuring plant diseases. Phytopathology 35, 665.

Kassler CAD. 2016 - Measure Pictures v. 1.0. CAD-KAS. http://www.cadkas.com (Accessed 13 May 2021).

Kurozawa C, Pavan MAP. 2005 - Doenças do tomateiro. In: Kimati H et al. (Eds.). Manual de fitopatologia: doenças de plantas cultivadas. 4. ed. São Paulo: Agronômica Ceres.

Lin L. 1989 - A concordance correlation coefficient to evaluate reproducibility. Biometrics 45, 255-268.

Lopes CA, Ávila AC. 2005 - Doenças do tomateiro. Embrapa Hortaliças.

Maluf WR, Miranda JEC, Bittencourt C. 1985 - Evaluation of Lycopersicon spp. accessions to Septoria leaf blight. Horticultura Brasileira 3, 9-11.

Martin-Hernandez AM, Dufresne M, Hugouvieux V, Melton R, Osbourn A. 2000 - Effects of targeted replacement of the tomatinase gene on the interaction of Septoria lycopersici with tomato plants. Molecular Plant-Microbe Interactions 13, 1301-1311. 
Mello SC, Takatsu A, Lopes CA. 1997 - Escala diagramática para avaliação da mancha-bacteriana do tomateiro. Fitopatologia Brasileira 23, 447-448.

Menge D, Makobe M, Shomari S, Tiedemann AV. 2013 - Development and validation of a diagrammatic scale for estimation of cashew blight for epidemiological studies. International Journal of Advanced Research 1, 26-38.

Nuñez AMP, Monteiro FP, Pacheco LP, Rodríguez GAA et al. 2017 - Development and validation of a diagrammatic scale to assess the severity of black rot of crucifers in kale. Journal of Phytopathology 165, 195-203.

Nutter Junior FW, Schultz PM. 1995 - Improving the accuracy and precision of disease assessments: selection of methods and use of computer-aided training programs. Canadian Journal of plant pathology 17, 174-184.

Nutter Junior FW, Worawitlikit O. 1989 - Disease. Pro: a computer program for evaluating and improving a person ability to assess disease proportion. Phytopathology 79, 1135.

Parker SK, Nutter FW, Gleason ML. 1997 - Directional spread of Septoria leaf spot in tomato rows. Plant disease 81, 272-276.

R Core Team. 2013 - R: A Language \& Environment for Statistical Computing. Vienna: R Foundation for Statistical Computing. Internet Resource: https://www.R-project.org/ (Accessed May 13, 2021).

Salgado M, Pozza EA, Lima LM, Pereira RTG, Pfenning LH. 2009 - Diagrammatic scale to evaluate severity of phoma leaf blight of coffee trees. Tropical Plant Pathology 34, 422-427.

Santos WF, Alves MC, Carvalho LG, Rios GFA, Fraga AC. 2010 - Elaboration and validation of a diagrammatic scale for epidemiological studies of Cercospora leaf spot of castor bean. Journal of Phytopathology 158, 403-408.

Sherwood RT, Berg CC, Hoover MR, Zeiders KE. 1983 - Illusions in visual assessment of Stagonospora leaf spot of orchardgrass. Phytopathology 73, 173-177.

Shrout PE, Fleiss JL. 1979 - Intraclass correlations: uses in assessing rater reliability. Psychological Bulletin 86, 420-428.

Sohi MS, Sokhi SS. 1974 - Morphological, physiological and pathological studies in Septoria lycopersici. Indian Phytopathology 26, 666-673.

Spolti P, Schneider L, Sanhueza RMV, Batzer JC et al. 2011 - Improving sooty blotch and flyspeck severity estimation on apple fruit with the aid of standard area diagrams. European Journal of Plant Pathology 129, 21-29.

Stevenson M, Nunes T, Sanchez J, Thornton R, Reiczigel J, Robison-Cox J, Sebastiani P. 2012 epiR: An R package for the analysis of epidemiological data. The Comprehensive $\mathrm{R}$ Archive Network website. Internet Resource: http://CRAN.R-project.org/package=epiR (accessed 13 May 2021).

Stevenson WR. 1991 - Septoria leaf spot. In: Jones, J.B., Jones, J.P., Stall, et al. Compendium of tomato diseases. St. Paul: APS, 22p.

Yadav NVS, de Vos SM, Bock CH, Wood BW. 2013 - Development and validation of standard area diagrams to aid assessment of pecan scab symptoms on fruit. Plant Pathology 62, 325335 . 